American J. of Engineering and Applied Sciences 2 (3): 559-564, 2009

ISSN 1941-7020

(C) 2009 Science Publications

\title{
Investigation of the Behavior of Tailings Earthen Dam Under Seismic Conditions
}

\author{
Debarghya Chakraborty and Deepankar Choudhury \\ Department of Civil Engineering, Indian Institute of Technology Bombay, \\ Powai, Mumbai-400076, India
}

\begin{abstract}
Problem statement: A number of tailings earthen dams have failed during past earthquakes. The failure of tailings dam ultimately results into the release of the stored tailings waste deposit in the surrounding locality. To reduce such damage of tailings earthen dam, a detail method of seismic analysis is very much essential which can be used reliably for the design and construction. Approach: To establish a detail method of static and seismic analysis for a tailings earthen dam, in this study both the static and seismic analysis were performed for a typical section of tailings earthen dam. The whole analysis was performed using various software packages like FLAC ${ }^{3 \mathrm{D}}$, TALREN 4, SEEP/W and SLOPE/W. Results: After FLAC ${ }^{3 \mathrm{D}}$ analysis it was observed that under the seismic loading condition the maximum displacement of the dam is about $66.7 \mathrm{~cm}$, whereas by using the Makdisi-Seed method the maximum displacement was obtained as $57 \mathrm{~cm}$. FLAC ${ }^{3 \mathrm{D}}$ analysis showed that the base level input acceleration gets amplified with the height of the dam and at the crest level the amplification is about three times. After slope stability analysis under seismic loading it was found that the factor of safety is 0.89 , but under the static loading condition the minimum value of factor of safety was obtained as 1.22. Conclusion/Recommendation: From this analysis it was clear that the dam was unsafe under the seismic loading.
\end{abstract}

Key words: Tailings earthen dam, seepage, amplification of acceleration, displacement magnitude, slope stability

\section{INTRODUCTION}

As per ICOLD ${ }^{[6]}$ several tailings earthen dams have failed during past earthquakes. The failure of tailings dam ultimately results into the release of the stored tailings waste deposit which often fairly dangerous because of the level of toxicity or corrosivity or both to human life and other living beings. To reduce such damage of tailings earthen dam, a detail method of seismic analysis is very much essential which can be used reliably for the design and construction.

From the literature review it is found that since the beginning of 1920 s and up to 1960 s 'Pseudo-static method' of analysis is most popular. But this method is too much simple and it dose not take into account the nature of the slope-forming material or the foundation material. In the year 1965, based on deformation characteristics, Newmark ${ }^{[13]}$ proposed 'Sliding block method'. Among other methods, 'Shear beam model' analysis is quite well known. This method was introduced by Mononobe ${ }^{[12]}$. Gazetas ${ }^{[3]}$ proposed an improved 'Inhomogeneous shear beam model' which can take care of the fact that the shear modulus in earth or rock-fill dams is not constant but increases with 2/3power of depth from the crest.

Clough and Chopra ${ }^{[2]}$ introduced the finite element method for two-dimensional plane-strain analysis for evaluating the dynamic response of an embankment assuming that it consists of linearly elastic, homogeneous, isotropic materials. Later on, several other researchers developed the finite element and finite difference method for non-linear, inelastic, nonhomogeneous, anisotropic behavior of materials under seismic conditions. Zeghal and Abdel-Ghaffar ${ }^{[21]}$ proposed a local-global finite element method of analysis for determination of the non-linear seismic behavior of earth dams. Ming and $\mathrm{Li}^{[11]}$ conducted a fully coupled finite element analysis of failure of Lower San Fernando Dam and examined the possible reason of the dam failure.

Rapid development of computer programs has revolutionized the earthquake engineering research. For example, several computer programs like $\mathrm{e}^{[5,8,14,18]}$ are used worldwide for the rigorous seismic analysis of earthen

Corresponding Author: Deepankar Choudhury, Department of Civil Engineering, Indian Institute of Technology Bombay, Powai, Mumbai-400076, India Tel: +91-22-2576 7335 Fax: +91-22-2576 7302 
dam. Seid-Karbasi and Byrne ${ }^{[17]}$ and Piao et al.$^{[15]}$ carried out dynamic analysis of the earthen dams using the finite difference method based computer code FLAC. Zhu et al. ${ }^{[22]}$ have presented a two-dimensional seismic stability for a levee embankment using finite element based program Plaxis ${ }^{[1]}$ and Teldyn. Though the computer programs are being used widely, proper validations of these results by suitable analytical and experimental results are always necessary.

To establish a detail method of analysis for a tailings earthen dam, in this study both the static and seismic analysis is performed for a typical section of tailings earthen dam. The whole analysis is performed using various software packages like FLAC ${ }^{3 \mathrm{D}}$, TALREN $4^{[19]}, \mathrm{SEEP} / \mathrm{W}^{[4]}$ and SLOPE/ $\mathrm{W}^{[4]}$. Among these FLAC $^{3 \mathrm{D}}$ (Fast Lagrangian Analysis of Continua in 3 Dimensions, Itasca $^{[7]}$ ) computer program is used widely.

\section{MATERIALS AND METHODS}

The static and seismic analysis of a typical section of water retention type tailings earthen dam of $44 \mathrm{~m}$ height and with a central core of $4 \mathrm{~m}$ is performed in this study. The slope of the upstream and the downstream side of the dam is 1:2.5. Figure 1 shows the tailings dam section. The input parameters used in the analysis presented in this study are shown in the Table 1.

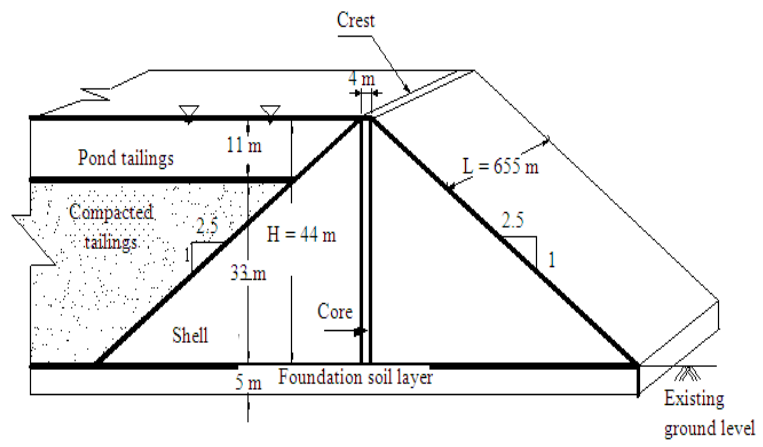

Fig. 1: Diagram of a typical tailings earthen dam

Table 1: List of dam parameters

\begin{tabular}{lccccc}
\hline & \multicolumn{5}{c}{ Dam soil } \\
& Shell & Core & $\begin{array}{l}\text { Pond } \\
\text { tailings }\end{array}$ & $\begin{array}{l}\text { Compacted } \\
\text { tailings }\end{array}$ & $\begin{array}{l}\text { Foundation } \\
\text { soil layer }\end{array}$ \\
Parameter & 18.30 & 16.40 & 19.00 & 19.00 & 18.30 \\
\hline Unit weight $\left(\mathrm{kN} \mathrm{m}^{-3}\right)$ & 31.25 & 35.00 & 14.70 & 14.70 & 31.25 \\
Cohesion value $(\mathrm{c})(\mathrm{kPa})$ & 28.00 & 28.00 & 12.00 & 15.20 & 28.00 \\
Angle of internal & & & & & \\
friction $(\phi)$ & 190.25 & 53.56 & 45.64 & 95.39 & 217.35 \\
Shear Modulus $(\mathrm{MPa})$ & 0.30 & 0.40 & 0.35 & 0.35 & 0.20 \\
Poisons ratio & 0.30 & 0.25 & 0.25 & 0.25 & 0.30 \\
Porosity & $1 \mathrm{e}-8$ & $1 \mathrm{e}-10$ & $1 \mathrm{e}-8$ & $1 \mathrm{e}-8$ & $1 \mathrm{e}-8$ \\
Permeability $(\mathrm{k})\left(\mathrm{m} \mathrm{sec}^{-1}\right)$ & & & & &
\end{tabular}

The dam with its various components is modeled in FLAC $^{3 \mathrm{D}}$ as shown in the Fig. 2. After modeling and applying the proper boundary conditions and the initial conditions the seepage analysis is performed. To verify the phreatic surface obtained by FLAC $^{3 \mathrm{D}}$ computer program, the same section is modeled in the SEEP/W software.

After simulating the phreatic surface in FLAC $^{3 \mathrm{D}}$ at first the static analysis under only the gravity loading is performed. Then the seismic analysis is performed. For the entire $\mathrm{FLAC}^{3 \mathrm{D}}$ analysis the Mohr-Coulomb plasticity model is used. In case of the seismic analysis the input acceleration time history is used at the base of the dam model for $30 \mathrm{sec}$ was of Taft earthquake (21st July, 1952) having magnitude of 7.7. The N21E component of the Taft earthquake with $1.527 \mathrm{~m} \mathrm{sec}^{-2}$ $(\approx 0.15 \mathrm{~g})$ maximum horizontal acceleration is shown in Fig. 3. The applied vertical acceleration is $1 / 2$ of the horizontal acceleration. For seismic analysis the earthquake excitations are given in various combinations. Such as "positive $\mathrm{x}$ acceleration along with positive $\mathrm{z}$ acceleration", "positive $\mathrm{x}$ acceleration along with negative $\mathrm{z}$ acceleration", "negative $\mathrm{x}$ acceleration along with positive $\mathrm{z}$ acceleration" and "only positive $\mathrm{x}$ acceleration". The damping ratio of the materials under seismic conditions is considered in the FLAC $^{3 \mathrm{D}}$ analysis as 0.05 .

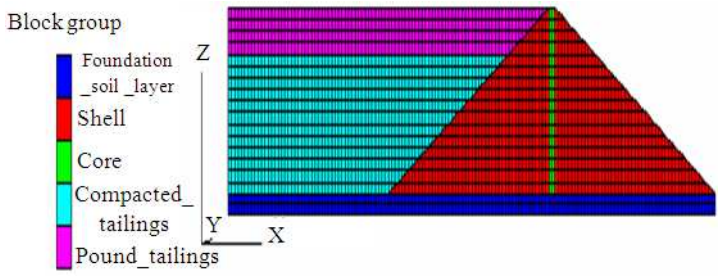

Fig. 2: Grid for tailings earth dam with foundation soil layer and compacted and pond tailings

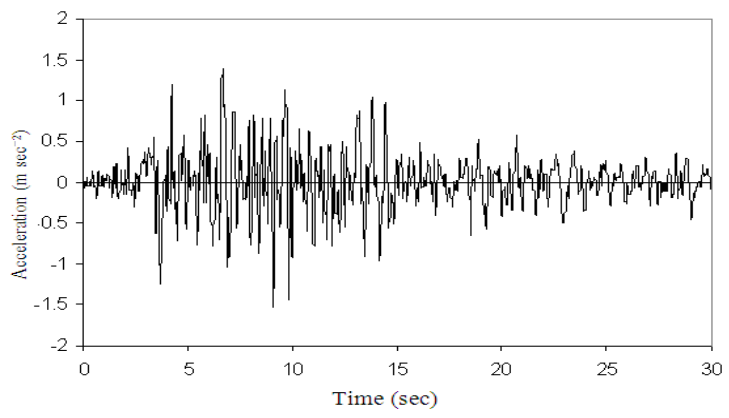

Fig. 3: Accelerogram with $1.527 \mathrm{~m} \mathrm{sec}^{-2}(\approx 0.15 \mathrm{~g})$ peak horizontal acceleration applied at the base of the dam 
To retain the non-reflecting seismic wave properties the dynamic free-field boundaries are established by using the 'apply ff' command. From the seismic analysis the displacement, acceleration time history, stresses, strains at various locations of the dam for the most critical load combination were obtained. The maximum displacement magnitude obtained by $\mathrm{FLAC}^{3 \mathrm{D}}$ analysis is compared with the maximum displacement obtained by the Makdisi and Seed ${ }^{[9]}$ method.

The static slope stability analysis is performed using FLAC ${ }^{3 \mathrm{D}}$, TALREN 4 and SLOPE/W. The minimum Factor of Safety (FS) value under the seismic loading condition is obtained using the TALREN 4 software package. Based on the recommendations made by Seed ${ }^{[16]}$, Terzaghi ${ }^{[20]}$ and Marcuson ${ }^{[10]}$ the horizontal seismic coefficient $\left(k_{h}\right)$ value is chosen as 0.15 for the TALREN 4 analysis. The vertical seismic coefficient $\left(\mathrm{k}_{\mathrm{v}}\right)$ value is applied as $50 \%$ of the horizontal seismic coefficient $\left(k_{h}\right)$ value $=0.075$. The Yield acceleration for the tailings earthen dam is also determined using TALREN 4.

\section{RESULTS}

The phreatic surface obtained from the FLAC ${ }^{3 \mathrm{D}}$ seepage analysis showed very good similarity with the phreatic surface developed in SEEP/W analysis. Figure 4 shows the contour of the pore water pressure from FLAC $^{3 \mathrm{D}}$ seepage analysis. Figure 5 shows the phreatic surface obtained in SEEP/W analysis. Figure 6 shows the contour of displacement magnitude after static analysis in FLAC $^{3 \mathrm{D}}$. From the static analysis after application of gravity loading the maximum displacement in the crest of the dam after static analysis is about $3.5 \mathrm{~cm}$.

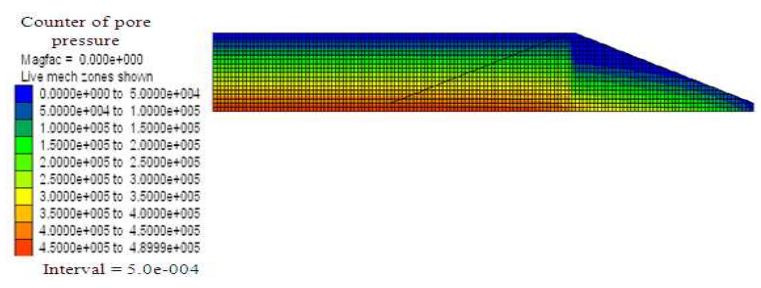

Fig. 4: Contour of pore water pressure (in $\mathrm{N} \mathrm{m}^{-2}$ ) obtained using the $\mathrm{FLAC}^{3 \mathrm{D}}$ seepage analysis

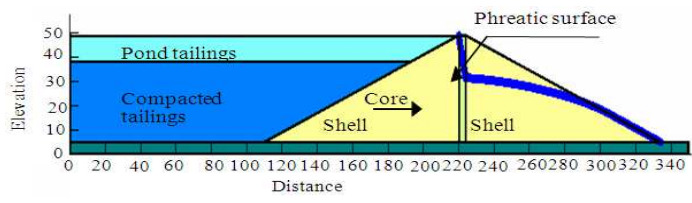

Fig. 5: Phreatic surface obtained after SEEP/W seepage analysis
Table 2 shows the maximum displacement of the tailings dam under various conditions of seismic loading obtained in FLAC $^{3 \mathrm{D}}$ analysis.

Figure 7 shows the contour of displacement magnitude after seismic analysis. It is observed that the maximum displacement magnitude is $66.7 \mathrm{~cm}$ in the crest region of the dam. Figure 8 shows the deformed shape (magnified twenty times for clarity) of the grids after $30 \mathrm{sec}$ of earthquake shaking.

\begin{tabular}{|c|c|c|c|}
\hline \multicolumn{4}{|c|}{ Maximum displacement (m) } \\
\hline $\begin{array}{l}\text { Positive } \mathrm{x}- \\
\text { acceleration and } \\
\text { positive } \mathrm{z} \\
\text {-acceleration } \\
0.667\end{array}$ & $\begin{array}{l}\text { Positive } \mathrm{x}- \\
\text { acceleration and } \\
\text { negative } \mathrm{z}- \\
\text { acceleration } \\
0.594\end{array}$ & $\begin{array}{l}\text { Negative } \mathrm{x} \text { - } \\
\text { acceleration and } \\
\text { positive } \\
\text { Z-acceleration } \\
0.549\end{array}$ & $\begin{array}{l}\text { Positive } \mathrm{x}- \\
\text { acceleration } \\
\text { only } \\
0.527\end{array}$ \\
\hline
\end{tabular}

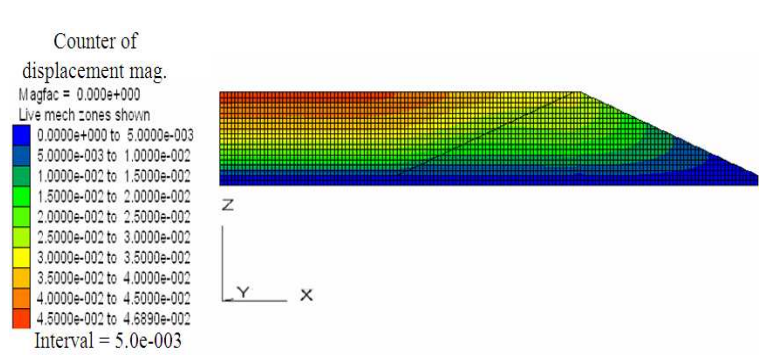

Fig. 6: Contour of displacement magnitude (in m) after static analysis

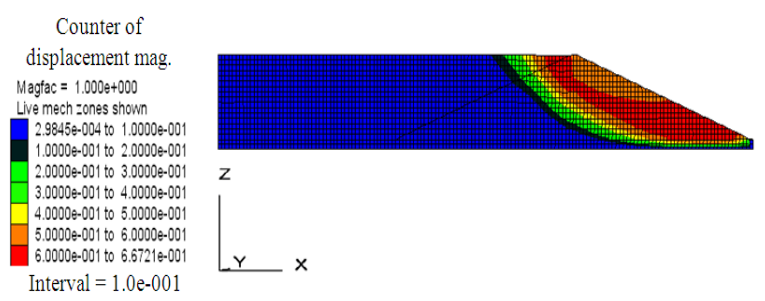

Fig. 7: Contour of displacement magnitude (in $\mathrm{m}$ ) after seismic analysis

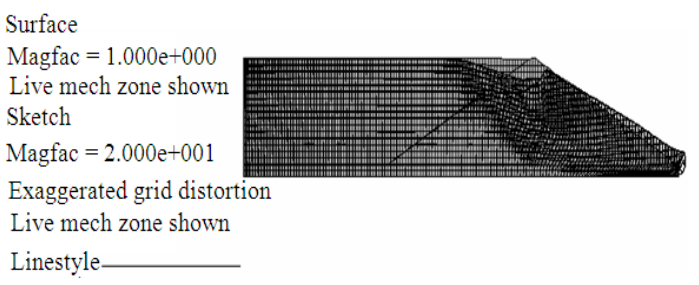

Fig. 8: Deformation after $30 \mathrm{sec}$ of earthquake shaking (magnified twenty times for clarity) 


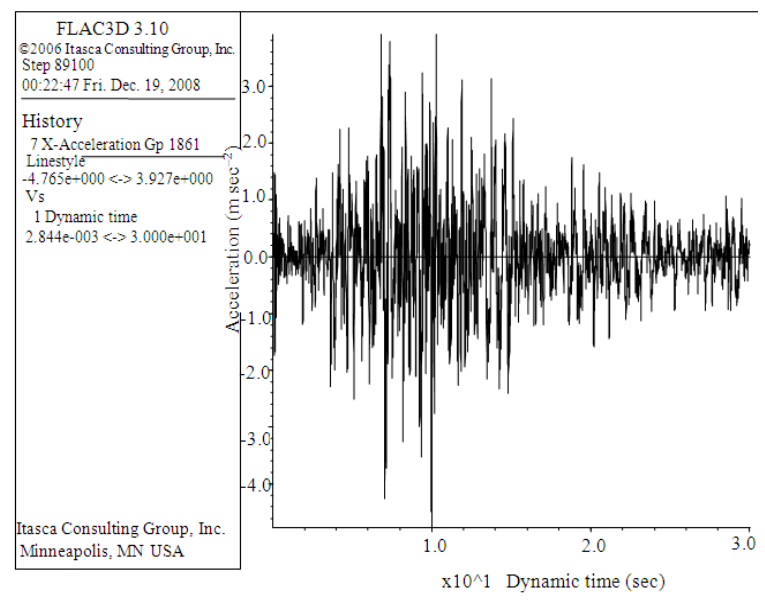

Fig. 9: Acceleration Vs dynamic time history at the crest level of the dam in $\mathrm{x}$-direction

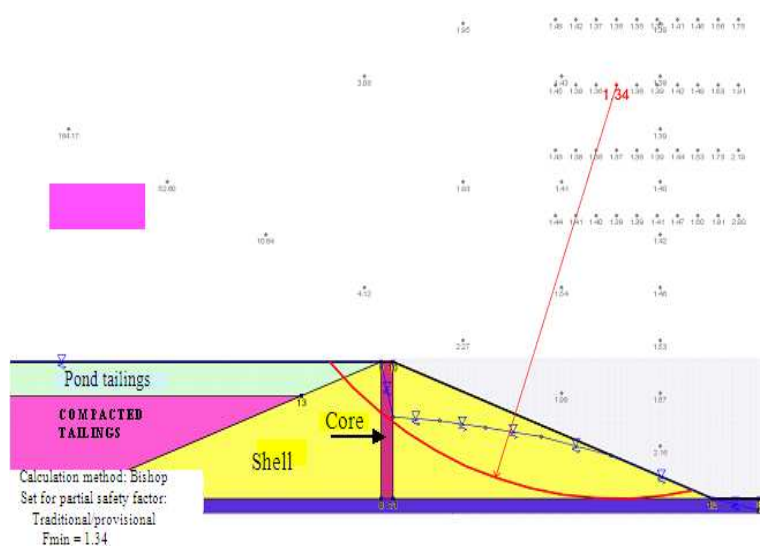

Fig. 10: Static slope stability analysis using TALREN 4

Table 3 shows the peak acceleration values in the $\mathrm{x}$-direction obtained at various height of the dam after the FLAC $^{3 \mathrm{D}}$ seismic analysis. Figure 9 shows the acceleration vs dynamic time history in the $\mathrm{x}$-direction at the crest level of the dam.

Table 4 shows the result of the static slope stability performed in three different software packages (FLAC $^{3 \mathrm{D}}$, TALREN 4 and SLOPE/W). Figure 10 shows the Factor of Safety value for the static slope stability analysis along with the critical slip surface found after TALREN 4 analysis. The minimum value of Factor of Safety under seismic loading condition using TALREN 4 is found as 0.89 . Figure 11 shows the Factor of Safety value for the seismic slope stability analysis along with the critical slip surface found after TALREN 4 analysis. The Yield acceleration value obtained as $0.1 \mathrm{~g}$ using the TALREN 4.
Table 3: Peak horizontal acceleration values at various heights of the dam

\begin{tabular}{llll}
\hline & Peak horizontal acceleration $\left(\mathrm{m} \mathrm{sec}^{-2}\right)$ \\
\hline$+11 \mathrm{~m}$ above & $+22 \mathrm{~m}$ above & $+33 \mathrm{~m}$ above & \\
the existing & the existing & the existing & Crest level of \\
ground level & ground level & ground level & the dam \\
1.793 & 2.27 & 3.656 & 4.765 \\
\hline
\end{tabular}

Table 4: FS values for static slope stability

Factor of Safety (FS) values

\begin{tabular}{lll}
\hline FLAC $^{3 \mathrm{D}}$ & TALREN 4 & SLOPE/W \\
1.22 & 1.34 & 1.386 \\
\hline
\end{tabular}

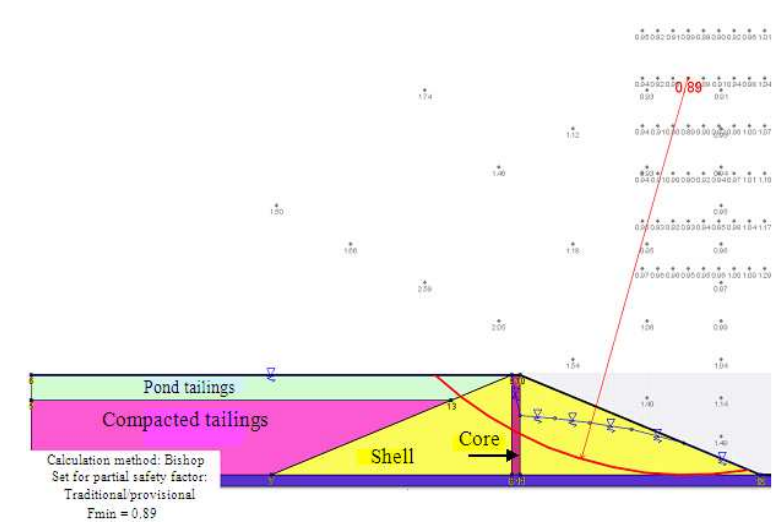

Fig. 11: Seismic slope stability analysis using TALREN 4 for $\mathrm{k}_{\mathrm{h}}=0.15$ and $\mathrm{k}_{\mathrm{v}}=0.075$

\section{DISCUSSION}

It is clear from the Table 2 that for the "positive $\mathrm{x}$ acceleration along with positive z-acceleration" seismic load applied at the base of the dam foundation the displacement magnitude is the maximum. So this condition is the most vulnerable to the tailings earthen dam. For this reason, the results of seismic analysis discussed here for that load combination.

By doing FLAC $^{3 \mathrm{D}}$ programming the value of fundamental period $\left(\mathrm{T}_{0}\right)$ of the dam is obtained as 0.34 sec. Using the Yield acceleration value of $0.1 \mathrm{~g}$ and the maximum acceleration value obtained by FLAC ${ }^{3 \mathrm{D}}$ analysis as $4.765 \mathrm{~m} \mathrm{sec}^{-2}(0.486 \mathrm{~g})$ along with the value of fundamental period of $0.34 \mathrm{sec}$ the permanent maximum displacement by the method proposed by Makdisi and Seed ${ }^{[9]}$ is obtained as $57 \mathrm{~cm}$.

\section{CONCLUSION}

From the results of the seepage analysis it can be concluded that the finite difference method based FLAC $^{3 \mathrm{D}}$ and finite element method based SEEP/W give similar results. 
After static and seismic analysis in $\mathrm{FLAC}^{3 \mathrm{D}}$ it can be concluded that seismic loading has its severe effect on the deformation of the dam. It is found that the maximum displacement in the crest region after seismic analysis is about 19 times higher than that after the static analysis. It is also found that the maximum permanent displacement after the seismic analysis obtained in $\mathrm{FLAC}^{3 \mathrm{D}}(66.7 \mathrm{~cm})$ is little higher than the result $(57 \mathrm{~cm})$ obtained using the method of determining the permanent displacement proposed by Makdisi and Seed ${ }^{[9]}$.

From the acceleration time history at various heights of the dam obtained by FLAC $^{3 \mathrm{D}}$ analysis shown that the base level input acceleration get amplified with the height of the dam and at the crest level the amplification is about three times.

After static slope stability analysis using $\mathrm{FLAC}^{3 \mathrm{D}}$, TALREN 4 and SLOPE/W it can be concluded that the FLAC $^{3 \mathrm{D}}$ is giving the minimum value of Factor of Safety as 1.22 for the tailings earthen dam. Whereas under the seismic slope stability analysis performed using the TALREN 4 is giving a Factor of Safety value of 0.89 only. But as per Seed ${ }^{[16]}$ under the seismic loading condition the minimum value of Factor of Safety should be 1.15 . Therefore, finally it can be concluded from this analysis that the tailings earthen dam is not safe under the condition of seismic loading.

\section{ACKNOWLEDGEMENT}

The researchers would like to express their sincere gratitude to Atomic Energy Regulatory Board (AERB), Mumbai, Government of India for providing fund to carry out this research.

\section{REFERENCES}

1. Brinkgreve, R.B.J., R. Al-Khoury, K.J. Bakker, P.G. Bonnier and P.J.W. Brand et al., 2002. PLAXIS 2D-version 8 full manual. Netherlands. http://www2.loot.co.za/shop/product.jsp?lsn=9058 095088

2. Clough, R.W. and A.K. Chopra, 1966. Earthquake stress analysis in earth dams. J. Eng. Mech., ASCE., 92: 197-211. http://nisee.berkeley.edu/elibrary/Text/300451

3. Gazetas, G., 1981. A new dynamic model for earth dams evaluated through case histories. Soils Foundat., 21: 67-78. http://ci.nii.ac.jp/naid/110003914595/

4. Geo-Slope, 2007. SEEP/W and SLOPE/W. Version 7.03, User's Guide, Geo-Slope International Ltd., Calgary, Atlanta.
5. Hudson, M., I.M. Idriss and M. Beikae, 1994. User's manual for QUAD4M. Center for Geotechnical Modeling, Department of Civil and Environmental Engineering, University of California, Davis, CA., USA.

$\mathrm{http} / / / \mathrm{cgm}$.engineering.ucdavis.edu/Publications/re ports/Quad4M_manual_rev2003.pdf

6. ICOLD, 2001. Tailings dams risk of dangerous occurrences. (Bulletin 121), International Commission on Large Dams, Paris. http://www.icold-cigb.net/

7. Itasca, 2006. Fast Lagrangian Analysis of Continua in 3 dimensions (FLAC ${ }^{3 \mathrm{D}}$ ), " Version 3.1, User's Guide, Itasca Consulting Group, Minneapolis, Minnesota, USA. http://www.atesindia.com/services/FLAC3D.htm

8. ITASCA, 2000. Fast lagrangian analysis of continua. Version 4, User's Guide, ITASCA Consulting Group, Minneapolis, Minnesota, USA. http://www.aimil.com/flac3d.aspx

9. Makdisi, F.I. and H.B. Seed, 1978. A simplified procedure for estimating dams and embankments earthquake-induced deformations. J. Geotech. Eng. Division $\quad$ ASCE., 104: 849-867. http://cedb.asce.org/cgi/WWWdisplay.cgi?5013898

10. Marcuson, W.F., 1981. Moderator's report for session on earth dams and stability of slopes under dynamic loads. Proceedings of the International Conference on Recent Advances in Geotechnical Earthquake Engineering and Soil Dynamics, St. Louis, Missouri, pp: 1175-1175.

11. Ming, H.Y. and X.S. Li, 2003. Fully coupled analysis of failure and remediation of lower San Fernando dam. J. Geotechnic. Eng. Div., ASCE., 129: 336-349. DOI: 10.1061/(ASCE)10900241(2003)129: 4(336)

12. Mononobe, H.A., 1936. Seismic stability of the earth dam. Proceeding of the 2nd Congress on Large Dams, (CLD’36), Washington DC., USA., pp: 435-442.

13. Newmark, N.M., 1965. Effects of earthquakes on dams and embankments. Geotechnique, 15: 139-160. http://www.civil.ubc.ca/liquefaction/Publications/H yropower\&Dams.pdf

14. Ordóñez, G.A., 2000. SHAKE2000: A computer program for the 1D analysis of geotechnical earthquake engineering problems. http://www.shake2000.com/index.htm

15. Piao, R., A.H. Rippe, B. Myers and K.W. Lane, 2006. Earth dam liquefaction and deformation analysis using numerical modeling. Proceeding of the Geo Congress (GC'06), ASCE., pp: 1-6. DOI: $10.1061 / 40803(187) 217$ 
16. Seed, H.B., 1979. Considerations in the earthquake-resistant design of earth and rockfill dams. Geotechnique, 29: 215-263.

17. Seid-Karbasi, M. and P. Byrne, 2004. Embankment dams and earthquakes. Hydropower Dams, 2: 96-102. http://www.civil.ubc.ca/liquefaction/Publications/H yropower\&Dams.pdf

18. TAGA soft Limited, 1998. TELDYN-Users' manual. Lafayette, California. http://www.tagasoft.com/

19. Terrasol Geotechnical Consulting Engineers, 2007. TALREN 4 user's guide, version 2.0.3. Montreuil Cedex, France.

http://www.terrasol.com/Anglais/main_software.ht $\mathrm{m}$

20. Terzaghi, K., 1950. Mechanism of landslides. In: Application of Geology to Engineering Practice, Sidney, P. and Berkey (Eds.). The Geological Society of America, New York, pp: 83-123. http://books.google.com.pk/books?id=CugJAQAAIAAJ $\& q=$ Paige,+ Sidney $+($ Chairman $),+$ Application + of + Geolo gy+to+Engineering + Practice $\& d q=$ Paige,+ Sidney $+($ Chair man),+Application+of+Geology+to+Engineering+Practi ce\&pgis $=1$ response of earth dams. Comput. Struct., 42: 569-579. DOI: 10.1016/0045-7949(92)90124-I

22. Zhu, Y., K. Lee and G.H. Collison, 2005. A 2D seismic stability and deformation analysis. Proceeding of the Geo-Frontiers, Jan. 24-26, ASCE., Austin, Texas, pp: 1-15. http://www.golder.com/archive/2005Geo_PTFI.pdf

21. Zeghal, M. and A.M. Abdel-Ghaffar, 1992. Localglobal finite element analysis of the seismic 